\title{
Remembrances of Raimond Castaing and his work
}

When my research professor, Jesse W.M. Dumond suggested that I construct an "electronic $\mathrm{X}$-ray probe" as part of my Ph.D. thesis, I had no idea of what he was talking about. The year was 1952. Dumond's friend and colleague, Pol Duwez had just returned from a trip to Europe where he had a chance meeting with André Guinier on the boat train from London to Paris. Guinier told him about a wonderful new analytical instrument that his student, Raimond Castaing, had recently developed and Duwez asked Dumond if he had any students who might want to work on development or applications of such an instrument. As it happened, I became that student, and this was the beginning of a long and continuous association with Professor Castaing's work.

As I became further involved in my thesis work, I became more and more aware of the remarkable thesis which Castaing had written. It provided my first introduction to electron optics, aberrations of electron lenses and the interaction of electron and X-ray beam with matter. Even today, the English translation which Pol Duwez and I published in 1955 is required reading for my students.

I first met Castaing at a small meeting of some of the people who were involved in early development of electron probe microanalyzers in the U.S., England and France. It was held in Washington, DC in 1958 and was sponsored by the U.S. Naval Research Laboratory and hosted by Verne Birks and L.S. Brooks. I had dinner with Castaing one evening and I tried to speak in French but soon found that Castaing understood English much better than I understood French !

My next meeting with Castaing was in 1962 at the University of Southern California where we were giving a summer course on Electron Probe Microanalysis. A that time, we had a few rooms at our faculty center for visitors and since Prof. Castaing was one of the invited speakers, I arranged for him to occupy one. He was suffering from jet lag due to the time difference between Paris and California so he woke very early and went outside to a small patio area outside each room. But alas the door locked behind him and he had no way to get back into the room except by climbing over the roof while dressed in his night clothes. He said later that morning "If a policeman had seen me he would shoot me!".

Our summer course was held just before the Third International Conference on X-Ray Optics and Microanalysis in Stanford. At this meeting, a lively discussion took place after a paper on a commercial instrument that was based on "afocal electron optics". Both Castaing and Cosslett took the speaker to task. My recollection is that Cosslett insisted that achieving the current densities that were stated with the use of such a long working distance violated the principles of electron optics. Castaing jumped to his feet and said "It violates the principles of ordinary 
optics". The company that manufactured this instrument disappeared a short time later and we have heard nothing about afocal electron optics since then.

I first visited Castaing's laboratory in 1963 about the time of the summer school in Cambridge on Electron Probe Microanalysis. At this time, I saw the Ion Microanalyzer and two electron microscopes that had been modified for imaging energy-loss electrons. Castaing described his ideas for experiments to be done with these instruments with great enthusiasm and we remained at the laboratory long after everyone else working in the building had gone home. Among the many ideas Castaing talked about at that time was the possibility of observing magnetic domains by replacing the mirror in the optical system by a specimen, the possibility for improved corrections in quantitative $X$-ray microanalysis by using low accelerating voltages, and possibilities for experiments to measure X-ray fluorescence yields. Of course, there were many other thoughts and ideas, but these few that I recall are indicative of the fact that he was constantly thinking about many subjects and ideas at the same time.

As it happened, one of the people working for CAMECA became upset by my visit to Castaing's laboratory because I was a consultant for Applied Research Laboratories, an American company that made competitive instruments. I found it amusing to think that anyone would believe I could learn the "secrets" of making charged-particle instruments during a one-day visit to Castaing's laboratory !

This brings me to an important point about the impact of Professor Castaing's work on science and engineering. His pioneering work led to the development of important commercial instruments for characterization of materials. At one time, there were nine different companies throughout the world making instruments for electron probe X-ray microanalysis, and thousands of commercial instruments were produced. In a similar way, work in Castaing's laboratory was primarily responsible for generating the first interest in Secondary Ion Mass spectrometry by manufacturers of commercial instruments.

The work of Castaing and his students, Henry and Slodzian, on charged-particle imaging spectrometers is a marvelous example of the best optics and what can be done with them for characterization of materials. In fact, the magnetic prism they used was the inspiration for the method of EELS employing a point-to-point focussing magnetic prism below the camera chamber which I tried on a old AEI electron microscope in 1967 while I was on a Sabbatical leave at the Cavendish Laboratory. The fact that this approach has been widely adopted for EELS in the conventional TEM is a tribute to the recognition by Castaing of the value of the prism as optical element for charged-particle instruments.

Professor Castaing and his work has had a profound influence on my life as it undoubtedly has had on the lives and the research work of many others. I trust that he will continue to generate ideas that will be of as great a value as the ones that he has already produced. 